\title{
GEOTECHNICAL HYBRID SIMULATION SYSTEM FOR ONE-DIMENSIONAL CONSOLIDATION ANALYSIS
}

\author{
Youngcheul Kwon $^{\text {i) }}$, Motoki Kazama ${ }^{\text {ii) }}$ and Ryosuke UzuokA ${ }^{\text {iii }}$
}

\begin{abstract}
A system for a hybrid consolidation simulation was developed to predict more realistically the nonlinear behavior of the consolidation settlement of soft clay, including a large strain consolidation problem. The hybrid simulation method can introduce the mechanical behavior of the soils directly by combining numerical analysis and the soil element test in an online state. In this paper, a fundamental study to apply the hybrid simulation method to the consolidation settlement problem, a basic concept, and the corresponding algorithm and components are presented. Furthermore, using preconsolidated Kaolinite clays, verification studies were also conducted in the laboratory to verify the operational performance and data reliability of the system. On the basis of the test results, we concluded that the new consolidation analysis system using the hybrid simulation concept provided an adequate performance in the reproduction of the consolidation behavior of preconsolidated Kaolinite clays in the aspect of the dissipation of excess pore water pressure and corresponding consolidation settlement.
\end{abstract}

Key words: clay, consolidation, consolidation test, (hybrid simulation), (online test), settlement, soft ground (IGC: D5/E2)

\section{INTRODUCTION}

In recent years, remarkable advances in numerical analysis in geotechnical engineering have been made by virtue of the methodological development and improvement of computer efficiency. In many cases, the accuracy of numerical analysis greatly relies upon the modeling of the mechanical behavior of the materials. Conventionally, the soil constitutive relations for numerical analysis are obtained through the idealization of laboratory test results. However, several uncertainties in the compressibility of natural clay have also been recognized. Figure 1 depicts two representative examples of the uncertain aspect of the stress-stress relation during the compression. Figure 1(a) shows a stress-strain relation obtained from the test embankment at Berthierville in Quebec, Canada. Kabbaj et al. (1988) reported that pore water pressure increased even after the end of the construction while the effective stress decreased when the in-situ stress condition approached a consolidation yield pressure. Figure 1(b) shows a similar example of the increase in pore water pressure near the consolidation yield pressure of Osaka harbor clay obtained from a separated-type consolidation test in which the soils were divided into five interconnected specimens (Kang et al., 2001). These types of stress-strain relation are different from the typical behavior of natural clay, and could be connected to the limitations of conventional consolidation analysis, which assumes the linear relation before and after the yield pressure. Although several advanced models have been developed for detailed simulation of the consolidation behavior of soft clay, these models are still debatable and require complicated parameters for the simulation. Accordingly, Terzaghi's highly idealized consolidation theory is still used virtually even at a modern construction project, where corrected consolidation parameters based on the engineer's empirical judgment or several field measurement data are used.

Therefore, based on these problem perceptions, we have decided to develop a new simulation method to solve the one-dimensional consolidation settlement problem with high accuracy and versatility. It can be emphasized that the newly developed method has to propose a rational methodological approach which can substantially introduce the result of the element test of natural soil specimen to numerical analysis, including the uncertainty of mechanical behavior as shown in Fig. 1. As an alternative, the authors have paid attention to a hybrid simulation method to develop a new system for consolidation analysis. Basically, the responses of soils to external force (the change in excess pore water pressure in the consolidation problem) have been updated in real time in numerical analysis through repeated feedback analysis between the computation and the element test. As a result, de-

i) JSPS Fellow, Port and Airport Research Institute, Yokosuka, Japan (bent0417@hotmail.com).

ii) Professor, Dept. of Civil Engrg., Tohoku University, Sendai, Japan.

iii) Associate Professor, ditto.

The manuscript for this paper was received for review on May 29, 2006; approved on September $20,2007$.

Written discussions on this paper should be submitted before July 1, 2008 to the Japanese Geotechnical Society, 4-38-2, Sengoku, Bunkyo-ku, Tokyo 112-0011, Japan. Upon request the closing date may be extended one month. 

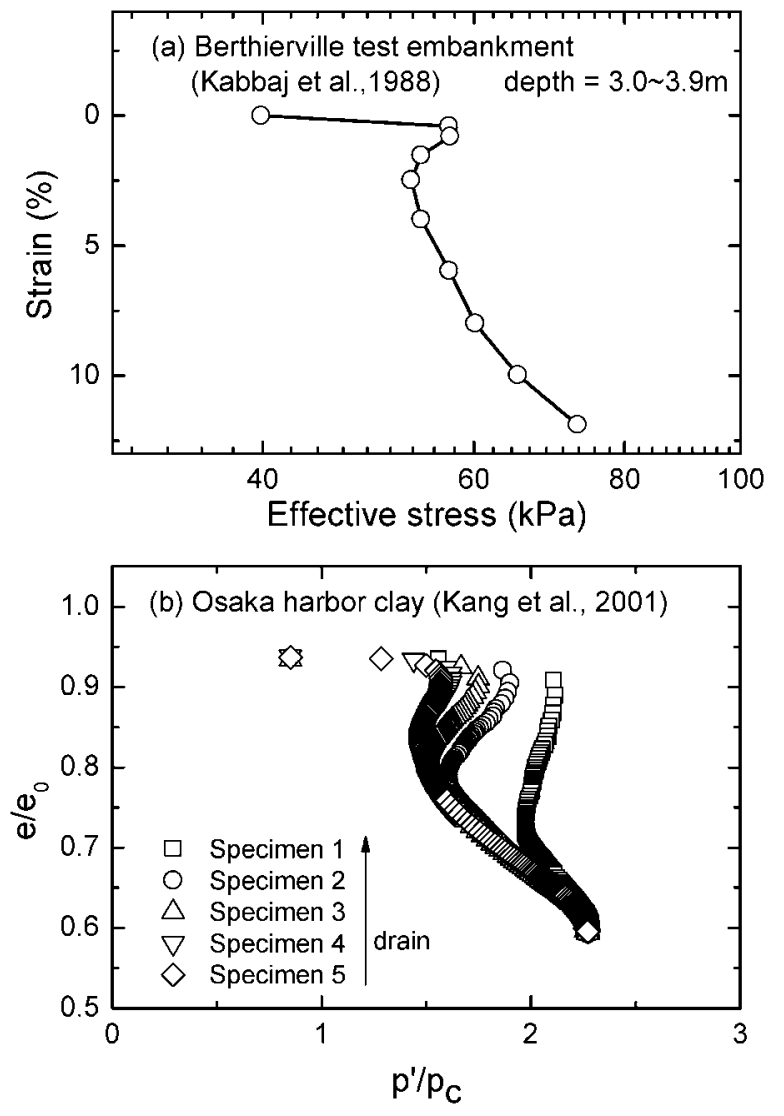

Fig. 1. Uncertainty of the stress strain relations

tailed consolidation analyses are possible without idealized constitutive relations and corresponding input parameters. In brief, the hybrid simulation is an integrated geotechnical analysis method which combines the numerical analysis and the element test to increase the accuracy of prediction in consolidation settlement.

In development of the hybrid simulation system, we addressed following two points: 1) the complicated soil behavior, especially near the consolidation yield pressure, must be considered in detail in the numerical analysis ; 2) use of complicated parameters must be avoided, if possible. This paper presents the concept of hybrid simulation for one-dimensional consolidation analysis including hardware and software components. Furthermore, sample problems carried out for system verification are also described.

\section{GEOTECHNICAL HYBRID SIMULATION FOR THE CONSOLIDATION PROBLEM}

A real-time online testing method was proposed by Hakuno and Shidawara (1969) to conduct seismic analysis while repeatedly updating the responses of the specimens. In their method, the resistance force of the specimen to the external force at a certain moment was directly introduced in numerical analysis instead of using constitutive relations obtained through idealization of the laboratory test results. From their first trial, their method has been estimated as an alternative to overcome a defect of present constitutive relations in seismic analysis. The method, one of the numerical experiments, has been called the 'online test' because the numerical analysis and the element tests have to be interconnected in an online state for the feedback analysis between the computations and the experiments.

Analyses without the constitutive models are possible through dealing with all degrees-of-freedom (DOF) with the online testing layer. However, complicated and huge experimental devices and a long running time are required for the multi-layered geotechnical problems. Therefore, several limited DOFs have been replaced by the element tests to raise system efficiency in general. As the methodology includes both online (element) testing and conventional numerical analysis, this method has been called the 'hybrid simulation method.'

This method has been applied to seismic geotechnical problems till recently to conduct quantitative estimations of soil deformation under earthquake motions while updating the restoration force from the undisturbed soil specimens (Kusakabe and Morio, 1995; Yamaguchi et al., 2002; Sento et al., 2002; Kazama et al., 2004). Hybrid simulation of the static geotechnical problem including consolidation has not been carried out (Kwon et al., 2004).

Figure 2 shows the basic algorithm of hybrid simulation for the consolidation analysis developed by this study. A spatial discretization was taken into consideration, as shown in Fig. 2(a). The nodes remained at the center of their respective elements throughout the consolidation process, and the variables such as the vertical coordinates, the excess pore water pressure, and the void ratio were updated at the end of each time step.

As the first process of the simulation, the distribution of the void ratio with depth after the time increment $\Delta \mathrm{t}$ was calculated, using a continuous equation and the explicit difference scheme under the various analysis conditions. Then, the excess pore water pressure for the next time step was estimated by two different ways, that is, numerical computation and the online test. The online test will be arranged for the several layers that are hard to know the compression behavior: for example, where the effective stress is distributed near the consolidation yield pressure or where the special soils like highly organic soils are. Others will be treated as the numerical computation layer. In layers of numerical computation, the excess pore water pressure was obtained from the constitutive relations of compressibility (conventional stress-strain relations), just as in conventional numerical analysis. On the contrary, excess pore water pressure for the test layers was measured directly as the response of the soil specimen after generating the computed volumetric strain compulsorily, as illustrated in Fig. 2(b). Using these methods, the vector of the vertical effective stress for the next time step $\left\{\sigma_{j}^{\prime t+\Delta t}\right\}$ was assembled and repeatedly used for the computation.

Theoretically, there was no problem in measuring hydraulic conductivity at every time step, such as compressibility. However, a comparatively long time is re- 


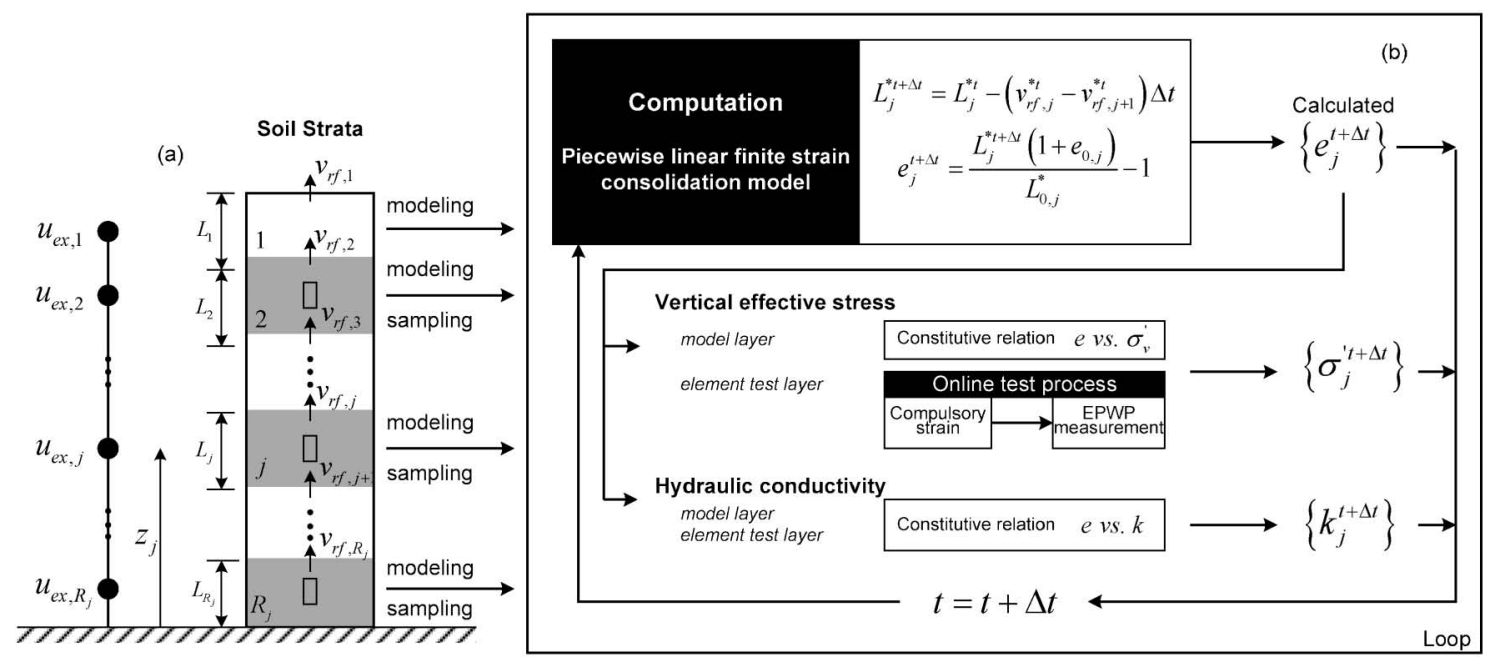

Fig. 2. Hybrid simulation for one-dimensional consolidation analysis

quired to reach the steady-state for measuring hydraulic conductivity, and as a result, a considerably long running time is inevitable to finish the entire process. In this study, therefore, the relationships between the void ratio and hydraulic conductivity were prepared before the hybrid simulation, and a vector of the hydraulic conductivity for the next time step $\left\{k_{\mathrm{j}}^{\mathrm{t}+\Delta \mathrm{t}}\right\}$ was estimated using these relationships both in the model layer and element testing layer, as illustrated in Fig. 2(b).

Through the abovementioned procedure of hybrid simulation, the stress-strain behavior of the element test layers is not required, and furthermore, detailed soil responses to external force can be directly introduced in the numerical analysis.

\section{SYSTEM ENVIRONMENT}

To establish the hybrid simulation system for consolidation analysis, three major parts were necessary: 1) computational body, 2) hardware components, and 3) software components.

\section{Computational Body for Consolidation Analysis}

A piecewise linear model for large strain, one-dimensional consolidation proposed by Fox and Berles (1997) provided the basic mathematical framework for the system. In their model, constitutive relations both in compressibility and hydraulic conductivity are defined by discrete data points. The details about this model can be found in their related publications.

In a convergence computation using the implicit difference method with the predictor and the corrector, iterative computations are indispensable in order to obtain a solution at a certain elapsed time. This implies that the computed volumetric strain should be generated repeatedly for the soil specimen during convergence analysis in the element test layer. However, repeated strain control during convergence analysis is also left as the history for the soil specimen. Therefore, the explicit finite difference method was adopted for the numerical integration in this study. Yong et al. (1984) showed that sufficient accuracy could be obtained by the explicit finite difference method, even though the implicit Crank-Nicholson method has been generally used to solve the piecewise linear consolidation model.

For the source coding, little modifications were necessary to accommodate the several specific conditions, such as the multi-layered soils, and the step or continuous external loading and modeling of the existence of the drain layer.

\section{Hardware Components for Element Test}

Figure 3(a) depicts the hardware configuration of the experimental equipment of the system. The system is divided into three major parts: 1) cell type consolidometer, 2) volumetric strain control device (VSCD), and 3) control and data acquisition unit. In order to carry out the online test, electrical pulses which are computed by the computational body are sent to the VSCD to change the location of the piston, and as a result, pore water will be drained from the specimen in the cell type consolidometer. When complete the drainage, displacements and excess pore water pressures of each device are measured. Finally, these measured data will be used for the computation of next time step, and the system can make the progress of the online test.

First, despite the widespread use of the hydraulic cell consolidometer associated with a diaphragm and a bellofram loading system, several disadvantages have also been highlighted. Khan and Garge (1994) and Blewett et al. (2002) suggested two major shortcomings of the celltype consolidometer: 1) the possibility of the existence of entrapped air or water between the bellofram and the cell wall and 2) the discrepancies in pressure transmission. Because the system controls an infinitesimal movement of the pore water in the hybrid consolidation simulation, these shortcomings of the conventional cell-type consolidometer could lead to erroneous solutions. Therefore, 


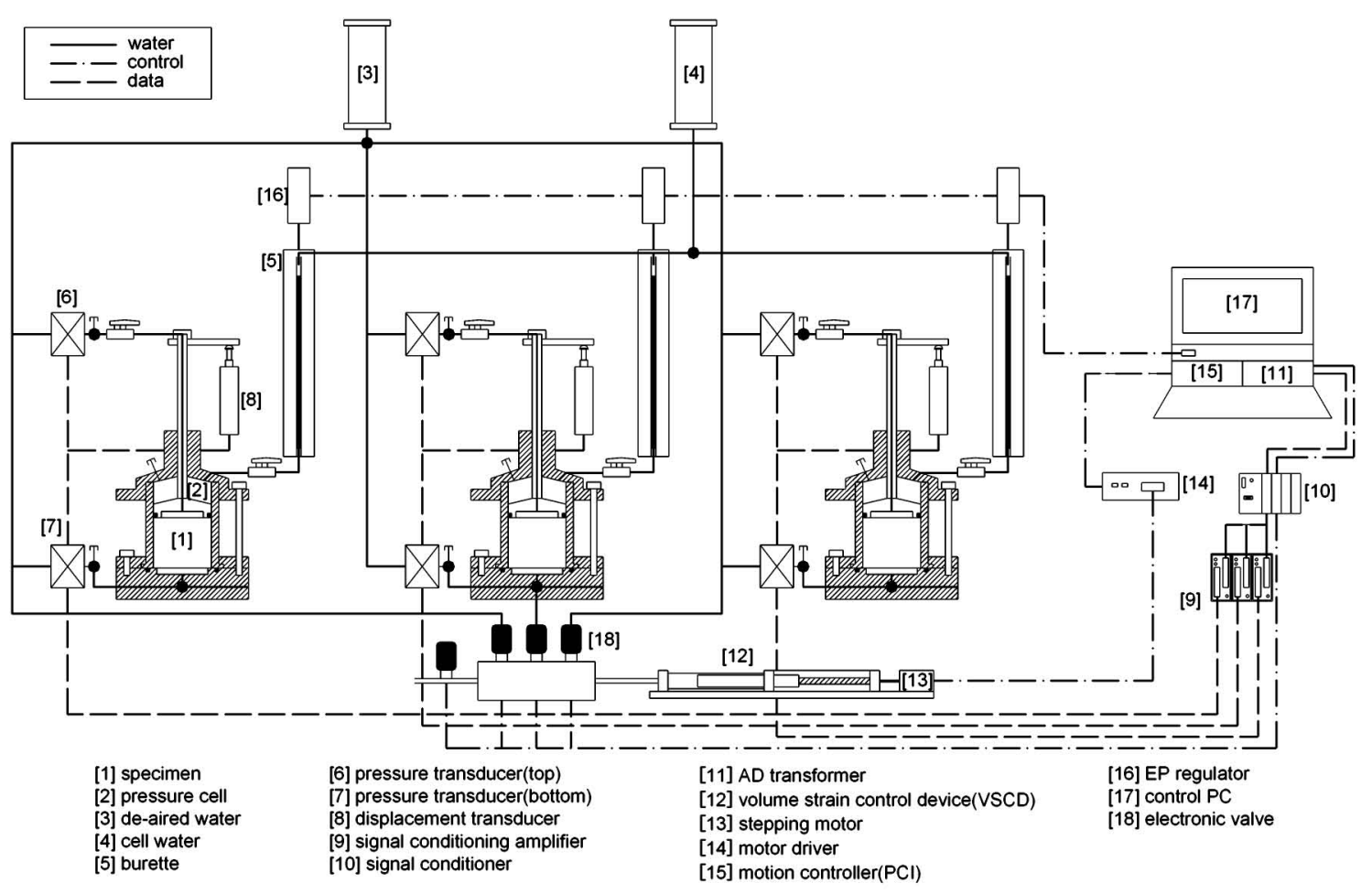

(a) Hardware configuration



(b) 5-DOF online consolidation testing system

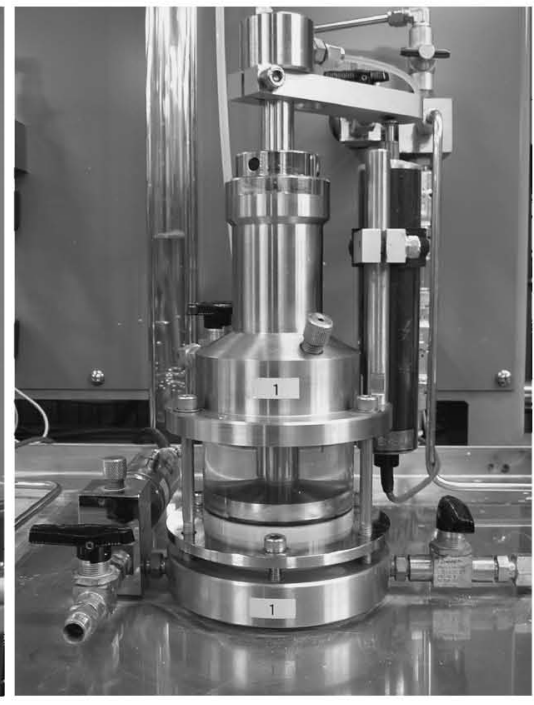

(c) Cell type consolidometer

Fig. 3. Hybrid consolidation simulation system

we designed a new cell-type consolidometer to improve the accuracy in control of the volumetric strain on the basis of modifying the conventional hydraulic cell consolidometer that was originally developed by Rowe and Barden (1966).

Figure 3(c) illustrates a general arrangement of the celltype consolidometer adopted in this study. The outer and inner diameters of the consolidation cell were $77 \mathrm{~mm}$ and $60 \mathrm{~mm}$, respectively, and the maximum height of the specimen could be set to $55 \mathrm{~mm}$. Two major aspects were modified to improve the abovementioned shortcomings. First, the cell was made of a transparent acrylic to certify the conditions of the specimen during the installation of the specimen for testing. It was possible to certify whether air had been entrapped. The O-ring seal was installed around the loading plate to separate the specimen and the pressure cell. In this apparatus, therefore, the pore water only moved by the control of the VSCD through the hollow spindle. Second, the hollow spindle moved up and down vertically, and ball bearings in the 
guide frame decreased friction. Consolidation pressure was transmitted to the specimen by applying hydraulic pressure to the loading plate. It was possible to generate accurate consolidation pressure, decreasing friction between the consolidation cell and O-ring seal, because EP transducers were controlled with small increments of voltage until the pore water pressure at the top and bottom of the soil specimen reached the target pressure. Therefore, considerable discrepancies between the applied pressure and transmitted pressure could be prevented.

One of the most important factors in realizing the concept of this simulation method is to generate the calculated displacement to specimen accurately. Therefore, a volumetric strain control device (VSCD) is used in the study. By using the VSCD described here, we have the ability to control the volume changes and pore water transport processes in the soil specimen. The VSCD consists of three major components: (1) a driving unit with a stepping motor; (2) a stainless steel syringe piston; and (3) a pore water cell. The motor is attached through the driving rail to the stainless steel syringe piston, and can be operated in both infusion and withdrawal modes. Both the injection and drainage of pore water are performed by these movements of piston connected with the stepping motor. The pore water cell was designed and made from transparent acrylic which makes it easy to observe the existence of air bubbles. The cell has a hole $16 \mathrm{~mm}$ in diameter and $256 \mathrm{~mm}$ in length. A stiff thick-walled cell with sufficient rigidity to endure high water pressure is thereby obtained. The cell has a port to which pipes and valves can be connected. The controlled volume port is connected to systems which require the volume to be controlled. The syringe piston has a $20 \mathrm{~mm}$ diameter, is 200 $\mathrm{mm}$ long and is made from stainless steel. The maximum possible piston travel is $260 \mathrm{~mm}$ giving a total syringe capacity of $33 \mathrm{~m} l$ in a single stroke. The piston is guided by a rotate prevention rod which is attached to the stainless block as shown in Fig. 4. From the resolution of the components including the stepping motor, the minimum solution of the VSCD was $6.3 \times 10^{-5} \mathrm{~cm}^{3} /$ pulse. With this resolution, the experimental equipment of the system could be used to control the infinitesimal strain.

\section{Software Components for Controlling Hybrid Simula- tion}

As explained before, hybrid simulation is an integrated simulation method that combines numerical analysis and the element test. Consequently, repetitive performances during running time including computation, device control, and data acquisition were indispensable to complete the simulation. Therefore, the system was fully automated for all experiment processes by a newly developed computer program.

\section{EXPERIMENTAL PROCEDURE}

1. Input data preparation: To prepare the constitutive relationship for compressibility (for numerical layers) and hydraulic conductivity (for all layers), consolidation tests such have been carried out.

To obtain the relationship between void ratio and hydraulic conductivity, an incremental loading consolidation test was carried out, and hydraulic conductivity was also estimated at the end of consolidation.

2. Specimen installation: The specimen was cut to a diameter of $60 \mathrm{~mm}$ and installed in the consolidation cell. After the consolidation cell was filled with deaired water, a loading plate was set up, and the existence of the entrapped air was certified.

3. Configuration of the analysis condition: The analysis conditions, including layer information, loading condition and initial condition were configured.

4. Saturation: To increase the degree of saturation of the specimen, backpressure $(100 \mathrm{kPa} \sim 200 \mathrm{kPa})$ was generated using the VSCD and EP transducers for at least $24 \mathrm{hrs}$.

5. Generation of the initial effective stress condition for the soil specimen: The initial vertical effective stress obtained from the initial computation was applied to the undisturbed soil specimen to produce the initial stress condition of the field.

6. Computation: The distribution of the void ratio with the depth was computed by consolidation analysis with proper time increments.

7. Hybrid simulation:

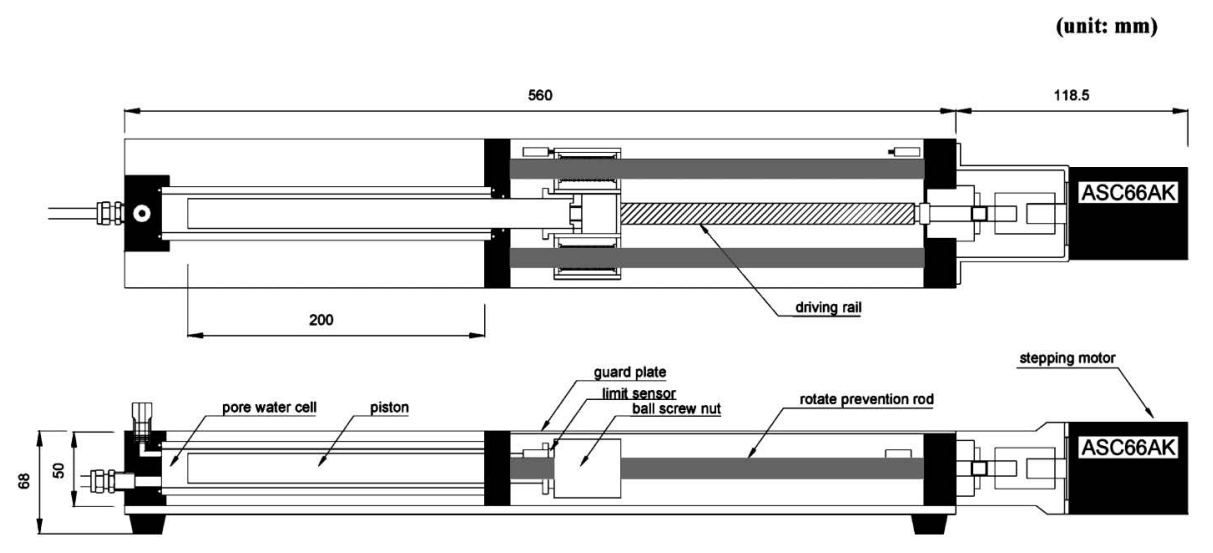

Fig. 4. Scheme of the volumetric strain control device, VSCD 
A. A void ratio vector for the next time step was calculated by excess pore water pressure, hydraulic conductivity matrix, and time increment using continuous equation. In computations of void ratio vector, it was assumed that hydraulic gradient was fixed during time increment $t$.

B. The number of pulses was calculated from the change of void ratio vector ( 1 pulse $=6.3 \times 10^{-5}$ $\mathrm{cm}^{3}$ ), and the stepping motor was controlled with a strain rate of $0.0069 \% / \mathrm{m}$ or a slower rate.

C. The excess pore water pressures of each device were measured after generation of volumetric strain. In hybrid simulation, because the drain for developing the computed volumetric strain was carried out by the VSCD compulsorily at the top and the bottom boundaries of specimen, nonuniformity in the effective stress could temporarily be observed. However, in hybrid simulation, it was assumed that the consolidation of each time step had to be completely finished. Therefore, the excess pore water pressure has to be measured after certifying that there was no rise in the pore water pressure, and the excess pore water pressure vector for the next time step was reassembled by these values.

D. The hydraulic conductive vector was reassembled from inputting the constitutive relationship.

E. If the elapsed time reaches the step loading time, the residual excess pore water pressure and incremental loading were added and used as initial excess pore water pressure for the next step.

8. Finally, the simulation loop was repeated until it satisfied the termination criterion.

\section{VERIFICATION STUDY IN THE LABORATORY}

\section{Consolidation Simulation of $100 \mathrm{~mm}$ Preconsolidated} Kaolin Specimen

A simulation was carried out for verification of the system reliability in aspects of the stress-strain behavior performance. A slurry state Kaolin specimen (1.5 times of the liquid limit) was consolidated under consolidation pressure of $180 \mathrm{kPa}$ for two weeks. A separated-type consolidation (STC) test with a $100 \mathrm{~mm}$ Kaolin specimen was conducted to compare with the hybrid simulation. The specimen was divided into five individual specimens of $20 \mathrm{~mm}$ in thickness. The specimens were subjected to an initial vertical effective stress of $40 \mathrm{kPa}$, and the incremental consolidation loading was subjected from 80 $\mathrm{kPa}$ to $640 \mathrm{kPa}$.

Figure 5 shows the compression curves obtained by four different consolidation tests. The results of the STC and hybrid simulation in the figure are of value when the five individual specimens are compared with a single specimen, which had a layer thickness of $100 \mathrm{~mm}$. In the figure, the compression curves from the STC test move downward with the elapsed time due to the time-dependent displacement. When comparison is made, the compression curve obtained from the hybrid simulation is

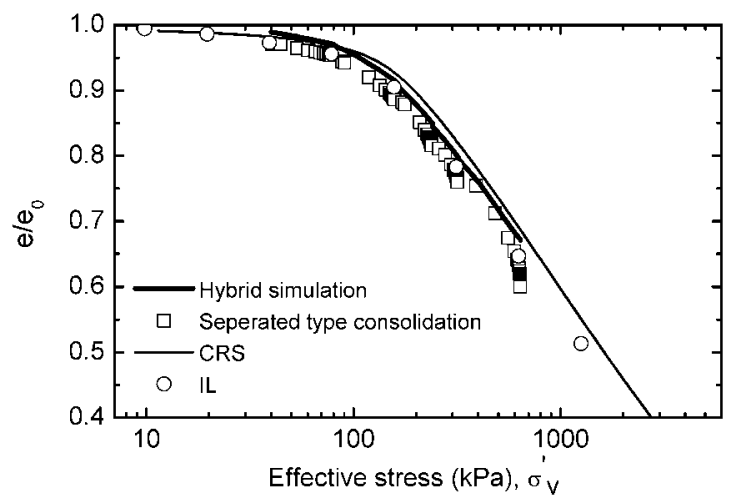

Fig. 5. Compression curves

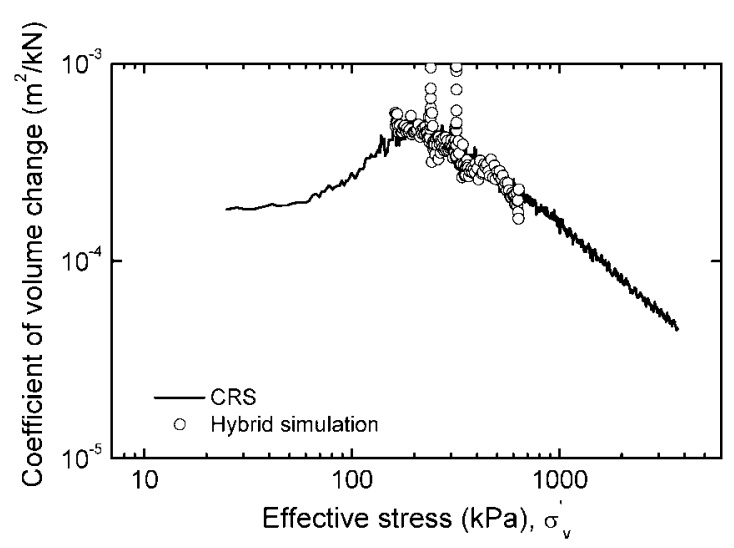

Fig. 6. Coefficient of volume change

similar to the CRS test and IL (incremental loading) test. Basically, consolidation settlement without dissipation of pore water pressure could not be considered in the hybrid simulation; the result might be taken as a matter of fact. Figure 6 illustrates the coefficient of volume change with the mean effective stress obtained from the CRS test and hybrid simulation in the normally consolidated region. The hybrid simulation reproduced the compressibility of the preconsolidated Kaolinite clay with good accuracy, though data dispersion was observed in the initial state of the step loading in the hybrid simulation because the volumetric strain increased greatly when compared with the dissipation of the excess pore water pressure.

Figure 7 shows the local degree of consolidation defined with respect to excess pore water pressure with elapsed time. When compared with the two test results, the hybrid simulation method simulated the dissipation of the pore water pressure of the Kaolin specimen well. Due to the hydraulic conductivity of the soil specimen in the hybrid simulation deduced from the results of CRS test, the possibility of an erroneous prediction of the rate of the consolidation was also raised from the test results.

\section{Illustrative Problem for the System Verification}

Figure 8(a) illustrates the geometry and the loading condition for the simulation problem. Horizontally homogeneous, three-layered soil with a layer height of 


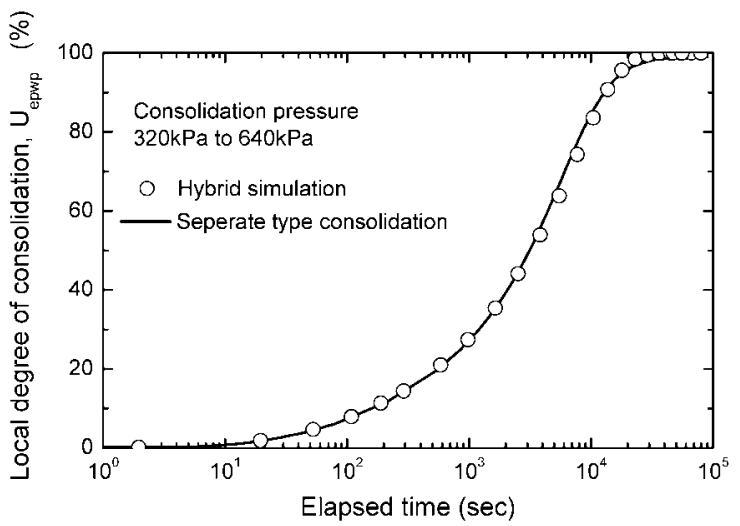

Fig. 7. Degree of consolidation

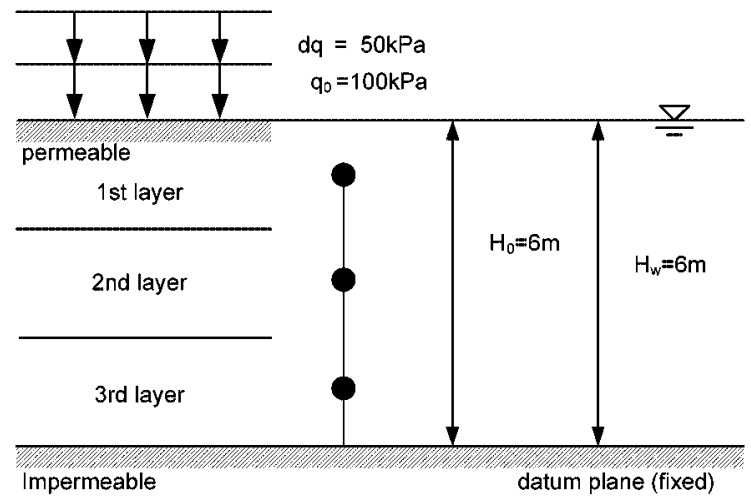

(a) Initial and loading condition

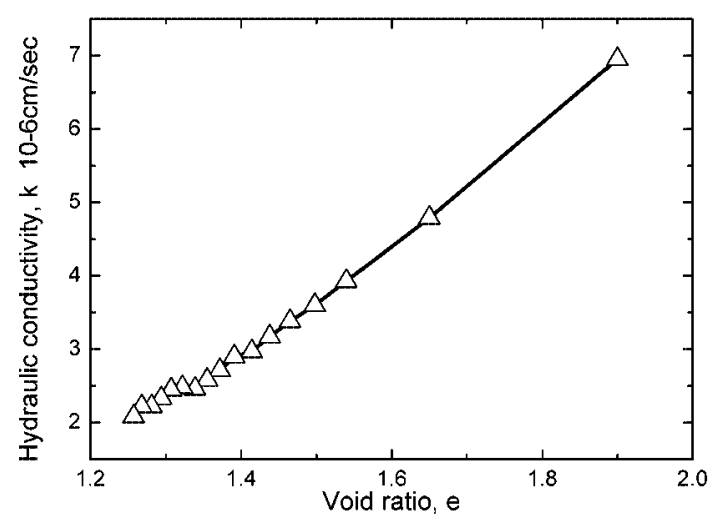

(b) Hydraulic conductivity

Fig. 8. Conditions for the simulation problem

$2 \mathrm{~m}$ was assumed for the hybrid simulation. The soil was subjected to an initial vertical effective stress of $100 \mathrm{kPa}$, and was fully consolidated by this stress. Consolidation pressure of $50 \mathrm{kPa}$ was loaded at the surface of the soil for 200 days. The top boundary, single-drain condition was employed, and the groundwater level was consistent with the ground surface in the initial condition. The testing specimen was obtained by applying a series of loading until the final consolidation pressure reached $100 \mathrm{kPa}$ under the double drain condition. In this problem, because all layers were treated as element test layer, material


Fig. 9. Example problems for the verification study

coefficient to define the compressibility was not required. But, the hydraulic conductivity for all layers had to be prepared to enter the simulation, and therefore we used the hydraulic conductivity as shown in Fig. 8(b), which was obtained by several laboratory tests.

Analysis results obtained from the hybrid simulation, numerical analysis, and IL consolidation test are summarized in Fig. 9. First, Fig. 9(a) depicts the relationship between the void ratio and the vertical effective stress obtained as the result of the hybrid simulation, which employed an infinitesimal movement of pore water by force. The relationship obtained from the IL consolidation test was also plotted in the figures to make a comparison. Data acquired by the hybrid simulation system showed close agreement for each soil layer. Figure 9(b) shows a comparison of the average degree of consolidation by the hybrid simulation system and the numerical solution of the nonlinear consolidation theory proposed by Fox and Berles (1997). The average degree of consolidation was defined with respect to the present vertical strain and the final vertical strain. Despite the fact that the hybrid simulation was faster in consolidation behavior than that of numerical analysis by a system compliance such as expansion of pipe lines and the lack of de-airation, the values were in relatively close agreement.

We concluded, therefore, that the comparisons in Fig. 9 demonstrated that hybrid simulation provides an adequate performance in the reproduction of the consolidation behavior of Kaolinite in the aspect of the dissipation of excess pore water pressure and corresponding consolidation settlement. 


\section{SUMMARY AND CONCLUSION}

Applicability of a hybrid simulation method for onedimensional consolidation analysis including a large strain problem was examined in this study. Basically, in hybrid simulation, responses of soils to the external force are updated in real time by numerical analysis through repeated feedback analysis between the computation and element test. As a result, detailed consolidation analyses are possible without idealized constitutive relations and corresponding input parameters. For the experimental system, several components of hardware and software were newly developed.

For the verification study, consolidation tests and illustrative analysis were carried out in the laboratory. From the results, we concluded that hybrid simulation for consolidation analysis provided an adequate performance in the reproduction of the consolidation behavior of preconsolidated Kaolinite in the aspect of the dissipation of excess pore water pressure and corresponding consolidation settlement.

However, to simplify the development process, we focused on the stress-strain relations of soft soil and the primary consolidation settlement caused by the dissipation of excess pore water pressure. In order to increase the eligibility of the system, improvement of the system was necessary to accommodate the secondary consolidation of soft soil and the constitutive relations in hydraulic conductivity from the specimen directly. Especially, in an effort to explain the cause of secondary (delayed) consolidation, research has focused on the viscosity of the clay (for example, Leroueil et al., 1985) and the increase of the excess pore water pressure by the decay of the soil skeleton (for example, Asaoka et al., 2000). Basically, in the hybrid simulation, as the consolidation settlement occurred only by the dissipation of the excess pore water pressure, we expect that the secondary settlement can be reproduced in hybrid simulation system in case that the increase of the excess pore water pressure causes the secondary consolidation. However, we need further research to establish a proper approach because the cause of secondary consolidation is still not well understood.

\section{REFERENCES}

1) Asaoka, A., Nakao, M., Noda, T. and Kaneda, K. (2000): Delayed compression/consolidation of natural clay due to degradation of soil structure. Soils and Foundations, 40(3), 75-85.

2) Blewett, J., McCarter, W. J., Chrisp, T. M. and Starrs, G. (2002): An automated and improved laboratory consolidation system, Can. Geotech. J., 39(3), 738-743.

3) Fox, P. J. and Berles, J. D. (1997): CS2: A piecewise-linear model for large strain consolidation, Int. J. for Numer. and Anal. Methods Geomech., 21(7), 453-475.

4) Hakuno, M. and Shidawara, M. (1969): Dynamic force-displacement relations of cantilever test piece applied by earthquake type external force, Proc. JSCE, (162), 11-20 (in Japanese).

5) Kabbaj, M., Tavenas, F. and Leroueil, S. (1988): In situ and laboratory stress-strain relationships, Geotechnique, 39(1), 83-100.

6) Kang, M., Tsuchida, T., Watabe, Y., Tanaka, H. and Miyazaki, S. (2001): Consolidation behavior of Osaka Pleistocene clay with welldeveloped structure by separated-type consolidometer of high capacity, Report of the Port and Horbour Research Institute, 40(2), 25-44.

7) Kazama, M., Sento, N., Uzuoka, R., Kwon, Y. and Sakamoto, K. (2004): Geotechnical hybrid simulation for predicting earthquake deformation of liquefiable ground both during and after, Proc. Int Conf. Cyclic Behaveior of Soils and Liquefaction Phenom., Balkema, Bochum, Germany, 479-487.

8) Khan, M. A. and Garga, V. K. (1994): A simple design for hydraulic consolidometer and volume gauge, Can. Geotech. J., 31(3), 769-772.

9) Kusakabe, S. and Morio, S. (1995): The development of a substructure on-line testing system for seismic response analysis of a geotechnical system, Soils and Foundations, JGS, 35(2), 117-125.

10) Kwon, Y., Kazama, M., Uzuoka, R. and Sento, N. (2004): An applicability of hybrid-online simulation method on the prediction of the consolidation settlement of soft clay, Proc. 15th South-East Asian Geotech. Conf., Bangkok, Thailand, 871-876.

11) Leroueil, S., Kabbaj, M., Tavenas, F. and Bouchard, R. (1985): Stress-strain-strain rate relation for the compressibility of sensitive natural clay, Geotechnique, 35(2), 159-180.

12) Rowe, P. W. and Barden, L. (1966): A new consolidation cell, Geotechnique, 16(2), 162-170.

13) Sento, N., Kazama, M., Fukumoto, S. and Saito, K. (2002): Geotechnical hybrid simulation of ground evaluation to be liquefiable by current conventional design method, Proc. US-Japan Sem. Seismic Disaster Mitigation in Urban Area by Geotech. Engrg., Alaska, USA, CD-ROM.

14) Yamaguchi, A., Kazama, M. and Kusakabe, S. (2002): On-line test of the seismic response at Kobe artificial island, J. of Geotech. Engrg., JSCE, (701), 181-195 (in Japanese).

15) Yong, R. N. and Ludwig, C. A. (1984): Large strain consolidation modeling of land subsidence, Proc. Symp. on Geotechnical Aspects of Mass and Materials Transport, Bangkok, Thailand, 14-29. 